\title{
THE RULE OF ST. BENEDICT SEBAGAI MODEL FORMASI SPIRITUAL SEMINARI*
}

\author{
Meiliana Evita Benes**
}

\begin{abstract}
This research is based on the thought of a saint, St. Benedict, contained in a rule made in the context of monastery, the Rule of St. Benedict. This rule has shaped the spiritual life of God's people for dozens of centuries. The strong emphasis on the balance of ora et labora, prayer and work, made this pattern relevant till date. This rule is also used as an approach to the forming of the patterns of spiritual formation in seminaries. Theological education is closely related to the growth of God's people. Thus, seminary as one model of theological education needs to have a good pattern related to the spiritual formation of everyone in it. The condition of seminaries in the present era with a tendency to show more attention to academic formation than to spiritual formation can cause imbalance in the life of seminarians. The Rule of St. Benedict can be a reference model so that seminaries can carry out a balanced theological education process to ensure that the academic quality exists as a part of the wholistic spiritual life.
\end{abstract}

Keywords: ora et labora, seminary, spiritual formation, the Rule of St. Benedict.

Abstrak: Penelitian ini didasarkan oleh pemikiran seorang kudus, St. Benediktus yang tertuang dalam sebuah aturan yang dibuat dalam konteks biara, the Rule of St. Benedict. Aturan ini telah membentuk kehidupan spiritual umat Tuhan selama belasan abad. Penekanan yang

* Artikel ini merupakan bagian dari tesis pada program studi Magister Divinitas yang telah diuji di Sekolah Tinggi Teologi Amanat Agung.

** Penulis adalah mahasiswa pascasarjana Sekolah Tinggi Teologi Amanat Agung dan melayani di Sekolah Kasih Yobel Singkawang. Penulis dapat dihubungi melalui email:meiliana01evita@gmail.com. 
kuat pada keseimbangan ora et labora, berdoa dan bekerja, membuat pola ini dapat digunakan hingga saat ini. Aturan ini juga digunakan sebagai pendekatan untuk membentuk pola formasi spiritual di seminari. Pendidikan teologi memiliki kaitan yang erat dengan pertumbuhan umat Tuhan. Dengan demikian, seminari sebagai salah satu model dari pendidikan teologi perlu memiliki sebuah pola yang baik terkait dengan formasi spiritual setiap orang di dalamnya. Kondisi seminari pada masa kini yang menunjukkan kecenderungan perhatian pada formasi akademik daripada formasi spiritual dapat mengakibatkan ketidakseimbangan dalam kehidupan para seminaris. The Rule of St. Benedict dapat menjadi sebuah model acuan agar seminari dapat menjalankan proses pendidikan teologi secara seimbang guna memastikan bahwa kualitas akademik hadir sebagai bagian dalam kehidupan spiritual secara holistik.

Kata-kata kunci: ora et labora, seminari, formasi spiritual, The Rule of St. Benedict.

\section{Pendahuluan}

Penelusuran sejarah memperlihatkan bahwa peradaban kekristenan yang signifikan selalu terkait dengan pembelajaran Kitab Suci. Pembelajaran ini menuntut orang-orang untuk memupuk sebuah hidup yang baik dengan melakukan berbagai disiplin. Di masa kekristenan mulamula, pembacaan Kitab Suci merupakan hal yang digunakan sebagai landasan pertumbuhan iman dan kerohanian orang percaya. ${ }^{1} \mathrm{Hal}$ ini menunjukkan sebuah keniscayaan bahwa pertumbuhan kekristenan selalu berbanding lurus dengan pertumbuhan dalam disiplin rohani.

1. Casthelia Kartika, "Origen on Spiritual Reading of Scripture and Prayer as Divine Pedagogy for the Perfection of Life." (Disertasi D.Th., Lutheran Theological Seminary, 2017), 99. 
Setelah melewati berbagai kondisi, kekristenan tiba pada kondisi ketika umat Tuhan bertumbuh dalam pola biara, sebuah komunitas orang percaya yang menyerahkan diri untuk menghabiskan banyak waktu untuk berdoa, membaca firman, dan berbagi dengan sesama. ${ }^{2}$ Prinsip yang alkitabiah tentang komunitas Kristen ini sangat kuat dan bahkan menjadi dasar utama dalam pola kehidupan komunitas biara. Penekanan utama di dalam biara adalah keseimbangan antara hal-hal yang rohani dan praktik kehidupan sehari-hari seperti doa dan bekerja yang disebut sebagai tujuan utama manusia diciptakan. ${ }^{3}$ Maka, dapat dikatakan bahwa pola hidup yang seimbang merupakan sebuah dasar utama dari kehidupan sebuah komunitas Kristen saat itu.

Seiring dengan perkembangan peradaban, pendidikan teologi juga terus mengalami perubahan bentuk dan pola. Setelah periode abad pertengahan-masa di mana biara menjadi salah satu wadah untuk membentuk hidup spiritual umat Tuhan-kekristenan terus berkembang hingga abad ke-19 menjadi sebuah era yang menandai munculnya seminari khususnya di wilayah Amerika dan berpengaruh ke seluruh dunia. Meski demikian, pola hidup dalam konteks formasi spiritual di biara perlu untuk diperhatikan, karena biara merupakan irisan besar yang membentuk seminari masa kini.

Keberlangsungan seminari sebagai pusat pendidikan dari salah satu cabang keilmuan (teologi), rentan menghadapi permasalahan

2. Justo L. González, The History of Theological Education (Nashville: Abingdon, 2015), 30.

3. Gerald L. Sittser, Water from a Deep Well: Christian Spirituality from Early Martyrs to Modern Missionaries (Downers Grove: IVP Books, 2010), 97. 
ketidakseimbangan. Kondisi yang biasanya muncul adalah tendensi ketidakseimbangan antara studi teologi dan disiplin rohani lainnya sebagai hal yang memengaruhi kehidupan spiritual. Kondisi ketidakseimbangan terletak pada pergerakan antara studi teologi dan formasi spiritual yang berjalan secara tidak simultan.

Studi teologi sering dipandang sebagai akhir dari proses pembentukan di seminari, padahal seharusnya hal ini menjadi perpaduan yang kuat bersama dengan disiplin rohani lainnya (berdoa, pembacaan firman Tuhan, dan juga bekerja) sebagai bagian dari formasi spiritual. Secara sederhana dapat dikatakan bahwa sangat mungkin terjadi di dalam seminari kondisi formasi spiritual dan studi teologi yang berlangsung secara tidak seimbang dan berpengaruh secara langsung kepada karakter dan moralitas seorang seminaris.

Virginia Cetuk memaparkan bahwa, tanpa formasi spiritual, semua pelayanan yang dilakukan pada akhirnya akan gagal. ${ }^{4}$ Tanpa pertumbuhan spiritual, pelayanan hanya menuai kegagalan. Kegagalan yang dimaksud adalah ketika kondisi seminaris tidak diarahkan pada keserupaan dengan pribadi Kristus. Oleh sebab itu, seminari perlu memerhatikan agar pembentukan akademik menjadi bagian dari formasi spiritual yang matang secara seimbang, bukan sebagai fokus utama.

Seminari berada di tengah kondisi dunia yang semakin sekuler. Kondisi ini menjadikan formasi spiritual sebagai hal yang semakin penting untuk diperhatikan dan perlu dilakukan secara intensional. The Rule of St.

4. Virginia Samuel Cetuk, What to Expect in Seminary: Theological Education as Spiritual Formation (Nashville: Abingdon, 1998), 155. 
Benedict dengan gaya hidup yang diringkas dengan istilah ora et labora (berdoa dan bekerja) tetap menjadi sangat relevan bagi orang-orang yang berjuang untuk formasi spiritual yang baik. ${ }^{5}$ Tawaran mengenai berbagai aturan yang terdiri dari berbagai praksis (aksi dan refleksi) membuat rule ini tepat jika diterapkan dalam berbagai bentuk komunitas umat Allah. Doa dan bekerja merupakan sarana utama untuk membangun berbagai karakter yang berkualitas sebagai dasar relasi hidup bersama Allah. Beberapa keserupaan konteks dan latar belakang pendidikan teologi membuat rule ini dapat dijadikan pola yang sangat kuat dalam pembentukan spiritual orang-orang di seminari.

Seminari merupakan wadah yang penting bagi pertumbuhan umat Tuhan. The Rule of St. Benedict kemudian dilihat dapat menjadi sarana formatif yang dapat diperhatikan dalam formasi spiritual di seminari. Melihat tingkat urgensi yang tinggi dari sebuah seminari dalam pembentukan hidup spiritual umat Tuhan, maka pembahasan di dalam tulisan ini disusun ke dalam tiga bagian utama, yaitu: 1) Elaborasi sejarah Pendidikan Teologi secara khusus dalam bentuk seminari untuk menjelaskan fungsi seminari terkait dengan peran dalam pembentukan kehidupan spiritual para seminaris; 2) Pemaparan fungsi The Rule of St. Benedict sebagai sebuah upaya yang dilakukan secara intensional untuk membentuk kehidupan spiritual di seminari dengan cara melakukan penelusuran sejarah terkait dengan proses penerapan hingga dampak yang dihasilkan sehubungan dengan pola pembentukan spiritual dengan

5. Jonathan Wilson-Hartgrove, New Monasticism: What It Has to Say to Today's Church (Grand Rapids: Brazos, 2008), 47. 
harapan menemukan keseimbangan dalam pola seminari; 3) Tantangan dalam seminari dan sumbangsih gagasan dan pertimbangan akademis sehubungan dengan pola formasi spiritual yang dapat digunakan di tengahtengah seminari melalui penggunaan The Rule of St. Benedict.

Penelitian ini dilakukan dengan metode penelitian historis yang secara khusus membahas pemikiran St. Benediktus yang dituangkan dalam tatanan yang disebut sebagai The Rule of St. Benedict. Model metode yang secara khusus digunakan dalam penelitian ini adalah metode Integral. James E. Bradley dan Richard A. Muller memberikan sebuah saran agar penelitian sejarah dilakukan dengan metode Integral atau Organik untuk memahami secara sinkronik perkembangan ide utama dalam kekristenan. ${ }^{6}$ Model ini sangat berguna untuk melihat penggunaan sejarah gereja dengan melakukan proses rekonseptualisasi dalam skala penggunaan yang lebih luas. ${ }^{7}$ Metode ini cukup kompleks karena banyak melakukan dialog dengan isu-isu yang berkembang di sekitar topik penelitian. Keunggulan utama model ini adalah besarnya kemungkinan untuk memahami perkembangan gagasan yang berkembang di dalam periode sejarah. ${ }^{8}$ Penulis berharap bahwa melalui metode ini, penggunaan The Rule of St. Benedict di masa abad pertengahan dapat diterapkan di abad ke-21 ini dengan proses kontekstualisasi yang tepat.

6. James E. Bradley dan Richard A. Muller, Church History: An Introduction to Research, Reference Works, and Methods (Grand Rapids: Eerdmans, 1995), 31.

7. Bradley dan Muller, Church History, 31.

8. Bradley dan Muller, Church History, 32. 


\section{Sejarah Pendidikan Teologi (Seminari)}

Dalam sepanjang sejarah, model pendidikan teologi mengalami perkembangan yang signifikan. Pendidikan teologi dipahami sebagai sarana untuk memperlengkapi para pelayan dan pemimpin gereja untuk bersatu dalam iman dan pengetahuan akan Allah. ${ }^{9}$ Hal yang paling kuat bagi sebuah pendidikan teologi adalah terkait dengan pembentukan spiritualitas umat Tuhan. Secara umum, kehidupan spiritualitas dipahami sebagai keseluruhan hidup manusia yang terhubung dengan Allah di dalam Yesus Kristus melalui Roh Kudus yang berdiam dan dengan bertumbuh dalam komunitas orang percaya. Maka, tujuan utama pola pendidikan ini adalah menghasilkan hidup yang berpusat pada Allah dan juga kepada umat manusia. ${ }^{10}$

Dwight N. Hopkins melihat bahwa vokasi dari pendidikan teologi adalah menerima tradisi teologi dan kemudian membagikannya sebagai bagian hidup spiritual. ${ }^{11}$ Di dalam perkembangannya, pendidikan teologi perlu menyadari akan signifikansi kehadirannya di tengah budaya umat manusia. Kondisi spiritualitas di tengah budaya sangat mudah menghadapi perubahan. Meski demikian, pendidikan teologi hadir sebagai wadah untuk membentuk kualitas spiritual seseorang. Oleh sebab itu, penggabungan budaya dan hidup spiritual yang mudah berubah seharusnya membuat manusia sadar bahwa proses ini hanya bisa terjadi sebagai akibat kemitraan

9. David S. Dockery, ed., Theology, Church, and Ministry: A Handbook for Theological Education (Nashville: B\&H, 2017), 18.

10. Columba Stewart, Prayer and Community: The Benedictine Tradition (Maryknoll: Orbis, 1998), 12.

11. Dwight N. Hopkins, "The Purposes of Theological Education," Theological Education 51, no. 2 (2018): 39. 
antara Allah yang berkuasa dan usaha manusia untuk berpartisipasi di dalamnya. ${ }^{12}$ Hopkins menyatakan bahwa hal mendasar yang perlu diperhatikan terkait dengan fungsi untuk memperlengkapi para mahasiswa teologi untuk bertumbuh secara mandiri dalam hidup spiritual adalah melalui praktik doa dan pelayanan kepada sesama. ${ }^{13}$ Praktik ini dilakukan sebagai aspek warisan yang ditemui di sepanjang sejarah formasi spiritual gereja di segala zaman.

Di masa pascareformasi Kristen, Gereja Protestan juga mengalami beberapa perubahan terkait dengan formasi spiritual umat Tuhan. ${ }^{14}$ Philipp Jacob Spener (1635-1705), Bapa Pietisme, mendirikan sekolah teologi Protestan atau yang dikenal sebagai seminari. ${ }^{15}$ Konsep seminari ini muncul sebagai tanggapan atas pola reformasi yang sangat cair terkait dengan pengajaran doktrin tanpa sebuah hidup kaku khas biara di masa abad pertengahan. ${ }^{16}$ Pergerakan pendidikan teologi dalam sepanjang sejarah

12. Hopkins, "The Purposes of Theological Education," 42.

13. Hopkins, "The Purposes of Theological Education," 42. Dari sebelas hal yang dinilai Hopkins perlu dilakukan di tengah pendidikan teologi, praktik yang berasal dari warisi tradisi, yaitu doa dan melayani sesama merupakan hal yang paling penting sebagai bagian dari pendidikan teologi.

14. Formasi spiritual adalah istilah yang pada mulanya digunakan oleh Gereja Katolik Roma, kemudian diadaptasi oleh kaum Protestan sejak Vatikan II. Istilah ini hendak menunjukkan betapa penting pemupukan hidup spiritual dilakukan dengan sengaja dan terstruktur. Tidak ada metode ringkas untuk memiliki hidup spiritual yang baik, selalu ada banyak proses yang dilewati, baik secara pribadi maupun secara komunal. Pembentukan ini terkait dengan keseluruhan hidup yang dilakukan dengan menjalani hidup pada tingkatan yang tertentu secara holistik. Hasil akhir dari formasi spiritual adalah hidup yang penuh di dalam Kristus dan menjadi serupa dengan-Nya.

15. Hinson, "The Spiritual Formation of the Minister as a Person." Review \& Ekspositor 70. no.1 (1973), 79.

16. Hinson, "The Spiritual Formation of the Minister as a Person," 79. 
mengalami sangat banyak perubahan dan berbagai penyesuaian berdasarkan tren zaman atas tanggapan dari pola-pola sebelumnya.

Penggunaan istilah "seminari" merupakan hal yang sangat berbeda antara yang dilakukan oleh kaum Katolik Roma dan kaum Protestan. Gereja Katolik melihat bahwa seminari adalah sarana untuk mempertahankan kondisi Roma Katolik agar umat tidak beralih kepercayaan dengan semangat kaum Protestan. Sedangkan, Spener memberikan arahan bahwa tujuan pendidikan para pelayan bagi umat Allah adalah terdidik dalam mata pelajaran yang akademis dan juga terlatih dalam kesalehan dan pendalaman firman Tuhan (piety and devotion). ${ }^{17}$ Spener mendorong agar seminari tidak menjadi sebuah tempat untuk berdebat, melainkan sebuah 'bengkel' atas karya Roh Kudus. ${ }^{18}$ Maka, seminari di masa ini memiliki tujuan untuk mengembalikan kodrat manusia untuk kembali kepada Allah melalui disiplin rohani dan juga studi teologi yang mumpuni.

Pendidikan teologi (seminari) perlu menyadari tugas dan fungsi yang terkait dengan pertumbuhan kedewasaan setiap orang percaya terkait dengan pengenalan akan Allah. Pertumbuhan spiritual mahasiswa teologi (seminaris) menjadi hal yang penting untuk diperhatikan karena memengaruhi secara langsung kehidupan spiritual jemaat yang dilayani. Oleh sebab itu, pendidikan teologi atau dalam hal ini merujuk secara

17. John D. Woodbridge dan Frank A. James III, Church History: From PreReformation to the Present Day: The Rise and Growth of the Church in Its Cultural, Intellectual, and Political Context 2 (Grand Papids: Zondervan, 2013), 454.

18. Woodbridge dan James III, Church History, 454. 
langsung pada seminari perlu memperhatikan formasi atau bentuk seperti apa yang digunakan dalam formasi spiritual para seminaris.

Pada pertengahan abad ke-19, di Amerika telah terdapat kurang lebih 50 seminari. ${ }^{19}$ Setiap seminari memiliki pola pengembangan masingmasing. Namun, hal yang perlu selalu dikembangkan dan dievaluasi adalah apakah formasi spiritual telah dilakukan dengan formatif sebagai aspek mendasar dari pendidikan teologi atau tidak. Jelas ini adalah keadaan yang ironis karena formasi spiritual mendapatkan berbagai hambatan dan kesulitan terkait dengan keberadaannya di tengah-tengah kurikulum pendidikan teologi dalam kurun 50 tahun terakhir ini terkait dengan formasi spiritualnya. ${ }^{20}$ Berkaca pada kondisi ini, maka formasi spiritual di dalam seminari seharusnya secara sengaja (intentionally) dan secara terpadu (integrally) dibentuk dalam pendidikan teologi. ${ }^{21}$

Seminari memerlukan dasar pemahaman bahwa formasi spiritual adalah proses yang dibentuk dengan sengaja dan dilaksanakan secara sistematis. Kehidupan spiritual meskipun bersifat sangat dinamis, tetap memerlukan format yang dapat digunakan untuk mengukur kualitas spiritual seseorang, terkhusus para seminaris. Beberapa hal yang perlu diperhatikan dalam pengukuran proses formasi spiritual adalah sebagai berikut,

harus mempertimbangkan penyusunan formasi yang melekat kepada Allah, memiliki kemampuan untuk mempertahankan

19. Hinson, "The Spiritual Formation of the Minister as a Person," 81.

20. Clemmons, "Spiritual Formation in Seminary Education," 46.

21. H. Frederick Reisz, Jr., "Assessing Spiritual Formation in Christian Seminary Communities: Lutheran Theological Southern Seminary," Theological Education 39, no. 2 (2003): 39. 
iman, kemampuan diferensiasi diri, kemampuan membentuk hubungan baik dengan sesama, nilai-nilai kebajikan, perubahan, kompetensi antar-budaya, kepekaan spiritual, permasalahan spiritual, kedewasaan iman, dan keterikatan murni dengan praktik spiritual. ${ }^{22}$

Sebelum melakukan pengukuran, seminari terlebih dahulu perlu kembali mengevaluasi porsi dan peran formasi spiritual sebagai bagian identitas dari sebuah seminari.

Salah satu keuntungan dari mempelajari sejarah adalah kesempatan untuk memakai apa yang sudah ada di masa lalu untuk diterapkan di masa sekarang. Model pendidikan teologi dalam biara memiliki kontribusi yang besar dalam kehidupan spiritualitas umat Tuhan. Orang-orang yang hidup dengan berbagai aturan dan model kedisiplinan, serta hidup yang teratur memiliki perkembangan kehidupan spiritualitas yang baik. Dalam kaitannya dengan perkembangan biara, penting untuk melihat bagaimana peran biara, terutama The Rule of St. Benedict dalam kaitannya dengan proses untuk membangun hidup spiritualitas yang intensional, sistematis, dan dinamis di tengah pendidikan seminari di masa kini.

\section{The Rule of St. Benedict}

The Rule of St. Benedict (RB) merupakan sekumpulan aturan yang terdiri atas 73 rules yang dibuat sebagai dasar dari kehidupan di dalam biara. Setiap aturan dibuat untuk menjaga kehidupan di dalam biara agar berjalan

22. Steven L. Porter dkk., "Measuring the Spiritual, Character, and Moral Formation of Seminarians: In Search of a Meta-Theory of Spiritual Change," Journal of Spiritual Formation and Soul Care 12, no. 1 (2019): 23. 
dengan teratur dan seimbang. Hal yang perlu dipahami terkait dengan aturan-aturan ini adalah bahwa St. Benediktus yang diduga kuat sebagai pembuat aturan ini tidak menuliskan secara murni aturan-aturan ini berdasarkan pemikirannya sendiri. Tulisannya banyak dipengaruhi oleh berbagai pendahulu kehidupan biara sebelumnya. Pemikiran St. Benediktus banyak dipengaruhi oleh aturan dalam Rule of Master yang ditulis jauh sebelum St. Benediktus. ${ }^{23}$ RB ini menarik karena tidak hanya sekadar berisi hal yang bersifat normatif, melainkan berperan formatif sebagai kekuatan besar yang mendorong dan membentuk kehidupan spiritual orang-orang yang hidup di dalam biara.

Salah satu cara untuk memahami rules ini adalah dengan melakukan pengklasifikasian secara sederhana, meski penulis awal tidak menyertakannya untuk memahami makna aturan ini dengan menyeluruh. ${ }^{24}$ Dasar pembagian yang dilakukan adalah berdasarkan

23. Meski ada banyak pedebatan mengenai hal ini, beberapa ahli kemudian setuju bahwa kedua rules ditulis oleh orang yang berbeda dan kemungkinan besar Rule of Master ditulis lebih dahulu. John Cassian, Agustinus, dan Basil merupakan orang-orang yang banyak memberi pengaruh bagi St. Benediktus. Salah satu penafsir RB, Terrence G. Kardong melihat bahwa ada banyak catatan yang terkait dengan para pendahulu di dalam pembahasan St. Benediktus. Namun, St. Benediktus menyusun aturan-aturan yang sudah ada dan menuangkannya secara otentik di dalam RB.

24. Columba Stewart memaparkan klasifikasi sederhana dari RB, sebagai berikut:

RB 1-7: Rules dimulai dengan penjelasan mengenai panggilan untuk hidup dalam biara. St. Benediktus memulai dengan penjelasan mengenai dirinya, otoritas seorang kepala biara sebagai pribadi yang bertanggung jawab atas kehidupan di biara, kemudian kualitas hidup yang harus dimiliki oleh setiap biarawan (RB 5-7).

RB 8-20: Bagian ini membahas liturgy of the hours atau yang dikenal sebagai opus Dei. St. Benediktus membagi setiap hari ke dalam beberapa waktu bagi setiap biarawan agar memiliki jam-jam khusus untuk mendekatkan diri kepada Allah 
keseragaman pembahasan di dalam rules. Setiap bagian menjadi sumber bagi pembentukan spiritualitas para biarawan. Di dalam tulisan ini, penulis akan mengklasifikasikan RB menjadi lima bagian utama. Setiap bagian akan menunjukkan keunikan setiap elemen di dalam RB sebagai landasan hidup spiritual.

\section{Mendengar sebagai Dasar Utama Mendekat kepada Allah}

Bagian ini adalah salah satu hal yang paling menarik dari RB. Pusat dari pengajaran dimulai dengan sebuah kata, yaitu Obsculta, verba Latin yang berarti 'dengarkanlah.' Praktik mendengarkan adalah inti dari pengajaran St. Benediktus. Proses mendengarkan yang dimaksud dijelaskan dengan sangat baik oleh Wil Derkse,

Listen [Obsculta/Ausculta] means listening very attentively, as when a doctor "auscultates" ["listens"] to a patient with a stethoscope. The goal of such attentive listening is to hear what a situation demands of us, and then to respond to it. ... To put it theologically: the word which has been heard must become incarnate, transformed into reality, into results. ${ }^{25}$

melalui pembacaan firman Tuhan dan doa. Pembagian menjadi beberapa waktu khusus, yaitu: Night Office/Nigil, Lauds, Prime, Terce, Sext, None, Vespers, dan Compline.

RB 21-67: Struktur dan praktik kehidupan sehari-hari diatur di dalam bagian yang panjang ini.

RB 68-73: Hal terakhir yang banyak dibahas oleh St. Benediktus adalah mengenai praktik kasih di tengah kehidupan berkomunitas antar satu saudara dengan saudara lainnya. Lih. Stewart, Prayer and Community, 20-21.

25. Wil Derkse, The Rule of Benedict for Beginners: Spirituality for Daily Life, terj. oleh Martin Kessler (Minnesota: Liturgical, 2003), 15. 
St. Benediktus menyadari bahwa untuk memiliki perubahan dalam hidup, seseorang harus memulai proses ini dengan mendengar. Hal yang didengarkan jelas merujuk kepada firman Tuhan yang diterima dalam manifestasi yang berbeda-beda, dalam bentuk teks Kitab Suci, literatur lainnya, maupun perkataan dan pengajaran dalam biara. ${ }^{26}$ Dengan kata lain, tanpa mendengarkan, manusia tidak akan dapat mengalami proses perubahan.

Hal mendasar dari 'mendengar' di dalam keseluruhan aturan yang disusun oleh St. Benediktus dituliskan dengan mengusung tema Kristus di atas segalanya sebagai tema utama dari keseluruhan kitab suci. ${ }^{27}$ St. Benediktus melihat bahwa Kristus adalah segalanya, di dalam Kristus sajalah manusia menjalankan kehidupan mereka. Kristus adalah awal dan akhir yang memanggil orang-orang untuk datang kepada Allah. ${ }^{28}$ Maka, intensi dasar dari pembuatan aturan-aturan ini terletak pada diri Kristus sendiri.

Kristus dikenal oleh St. Benediktus melalui kehidupan doa dan bekerja yang diatur dalam aturan-aturan dalam biara. Setiap aturan yang ada membantu orang percaya untuk mendengarkan firman dengan lebih baik, menghidupi Injil, dan dengan demikian sepenuhnya berpusat pada Kristus. ${ }^{29}$ Dengan penekanan ini, diharapkan bahwa orang percaya dapat bertumbuh secara optimal ke arah Kristus. Ketaatan di dalam firman menghasilkan sebuah hidup yang dipenuhi oleh kasih Allah.

26. Esther de Waal, Seeking God: The Way of St. Benedict (Norwich: Canterbury, 1999), 26.

27. Stewart, Prayer and Community, 28.

28. Waal, Seeking God, 15.

29. Waal, Seeking God, 18. 
Kunci agar seseorang mampu fokus mendengar dalam ketaatan adalah kesadaran bahwa di dalam mendengar, manusia menemukan Allah yang dicari oleh jiwa ini. ${ }^{30}$ Allah hadir dan membuka diri-Nya untuk ditemui oleh orang-orang yang bersungguh hati mencari-Nya dalam ketaatan sebagai wujud kesungguhan hati yang menantikan Dia. ${ }^{31}$ Dengan pemahaman bahwa Allah yang memanggil manusia untuk datang kepadaNya dan manusia seharusnya merespons dalam ketaatan, St. Benediktus mengakhiri sapaannya dengan sebuah tulisan yang indah mengenai hasil dari mengikuti pola yang ada di dalam biara,

49. Seiring dengan kemajuan di dalam kehidupan biara dan dalam iman, hati kita akan penuh dengan keindahan kasih yang tak terkatakan, yang memampukan kita untuk menyusuri pertandingan sesuai dengan perintah Allah. 50. Kemudian kita tidak akan pernah menjauh dari pengajaran-Nya dan kita akan bertekun dalam pengajaran di biara hingga meninggal. Demikian pula, kita akan mengambil bagian dalam penderitaan Kristus melalui kesabaran dan juga menjadi layak untuk menjadi rekan dalam kerajaan-Nya. Amin. ${ }^{32}$

Setiap hati manusia akan menemukan kepuasannya di dalam relasi dengan Allah melalui pendalaman firman Tuhan yang menjadi pola utama dalam rules. $^{33}$ Sekali lagi, prologue ini menjadi sebuah pernyataan utama mengenai dasar dari aturan yang ketat ini, bahwa mendekat kepada Allah dimulai dari mendengarkan Allah.

30. Waal, Seeking God, 27.

31. Waal, Seeking God, 27.

32. Terrence G. Kardong, Benedict's Rule: A Translation and Commentary (Collegeville: Liturgical, 1996), 5.

33. Adalbert De Vogue, Reading Saint Benedict: Reflections on the Rule (Minnesota: Cistercian, 1994), 35. 
Kasih sebagai Pembangun Kedisiplinan dan Kebajikan

Bagian pertama dari RB dibuka dengan penjelasan tentang kriteria seorang biarawan dan apa saja jenisnya. St. Benediktus membahas setidaknya ada tiga tipe hidup berkelompok, Coenobitic (hidup dalam aturan), Sarabaites (hidup bersama tanpa aturan yang mengikat), dan Gyrovagues (hidup berpindah-pindah dan menjalani hidup dalam keserakahan). ${ }^{34}$ Hidup berkelompok di dalam sebuah biara atau yang dikenal dengan Coenobitic Life mendapatkan penghargaan tertinggi dibandingkan dengan pola hidup lainnya. Alasannya adalah karena mengingat tingginya disiplin hidup yang terbangun di dalam komunitas. Kedisiplinan ditandai dengan ketatnya aturan dalam kehidupan bersama dan pentingnya kehadiran otoritas di biara (coenobitic life).

RB 2 menjelaskan mengenai pentingnya kehadiran kepala biara (bapa) di dalam biara sebagai refleksi Kristus di tengah-tengah biarawan. Hal yang penting terletak pada fungsi dan peran kepala biara, sebab kepala biara yang sejati adalah Kristus sendiri. ${ }^{35}$ Kasih Kristus dalam diri kepala biara dicerminkan dalam bentuk komitmen, kesungguhan yang memimpin orang kepada perubahan hidup. ${ }^{36}$ Bahkan, kasih yang dimaksud adalah kasih yang melayani, kasih yang terarah secara merata kepada semua pihak tanpa membeda-bedakan. Jadi, dapat dilihat bahwa refleksi kasih Allah adalah alasan utama dari disiplin yang dibangun oleh St. Benediktus.

34. Carolinne White, ed., The Rule of St Benedict (London: Penguin Classics, 2008), 11.

35. Vogue, Reading Saint Benedict, 46.

36. Derkse, The Rule of Benedict for Beginners, 48. 
Kehadiran Allah adalah hal yang sangat ultima dalam pengajaran St. Benediktus. Allah hadir dan memegang kendali sepenuhnya atas hidup manusia, bahkan sampai kepada hari penghakiman. Maka, tanpa memaknai bahwa Allah ada dan melihat, seseorang tidak mungkin menyadari bahwa hidupnya seharusnya selalu berada di bawah kendali Allah. Kesadaran akan kehadiran Allah membuat para biarawan dapat dengan luwes mempraktikkan kasih di tengah-tengah komunitas.

St. Benediktus kemudian menjelaskan bahwa hidup yang takut akan Allah di dalam kasih tentu menghasilkan berbagai kebajikan. Ketiga bentuk kebajikan utama dalam pengajaran St. Benediktus adalah ketaatan, praktik hening, dan kerendahan hati. ${ }^{37}$ Ketiga hal ini bersifat kristosentris, dalam arti mengikuti teladan dan pribadi Kristus. Seseorang yang berusaha mengasihi Allah akan hidup mengikuti Kristus di dalam hidupnya.

\section{Doa sebagai Wujud Kepekaan akan Kehadiran Allah}

RB banyak membahas mengenai tata cara ibadah yang dilakukan dalam biara yang sering disebut dengan Divine Office. Menarik untuk diperhatikan karena hal ini memiliki peranan yang sangat penting terkait dengan formasi spiritual para biarawan. Frasa 'Divine Office' adalah frasa yang memiliki banyak pengganti untuk menggambarkan pola spiritualitas dalam biara melalui kehidupan doa. Dalam sepanjang waktu dalam hidup di biara, St. Benediktus memakai perkataan pemazmur yang menunjukkan

37. Vogue, Reading Saint Benedict, 67. Vogue menjelaskan bahwa ketiga hal ini diadopsi oleh pemikiran John Cassian, salah seorang pendahulu sebelum St. Benediktus. Cassian menjelaskan bahwa untuk memiliki kerendahan hati, seseorang harus memiliki ketaatan yang akan diakhiri dengan praktik hening (on silence). 
bahwa ada tujuh waktu yang secara sengaja diberikan untuk datang menghadap kepada Allah melalui kehidupan yang penuh dengan doa (prayerful). "Tujuh kali dalam sehari aku memuji-muji Engkau, karena hukum-hukum-Mu yang adil”38 dilakukan secara literal oleh St. Benediktus.

Meski kuantitas memiliki peran yang penting, hal yang lebih penting terkait dengan kehidupan doa adalah kualitas doa itu sendiri. John Cassian dalam Institutio memberi penekanan bahwa yang terpenting adalah bagaimana seseorang dapat 'terus berdoa'. ${ }^{39}$ Kualitas ini menjadi nampak ketika para biarawan dapat melakukan waktu-waktu doa ini dengan disiplin dan dengan hati yang terarah kepada Tuhan. Hal ini senada dengan penjelasan dalam RB 19.1-2 dan 20.6,

1. Kita percaya bahwa Allah hadir di mana saja dan bahwa mata Tuhan melihat kepada yang baik dan yang jahat. 2. Kita harus, sungguh, meyakini penuh bahwa itu termasuk ketika kita hadir dalam Divine Office. ... 6. Jadi, marilah kita memerhatikan bagaimana kita bersikap di hadapan Allah dan para malaikat-Nya. ${ }^{40}$ Ketika kita berharap untuk meminta sesuatu kepada orang yang berkuasa, kita tidak akan melakukannya tanpa kerendahan hati dan rasa hormat/takut. 2. Lebih lagi seharusnya ketika kita menaikkan permohonan kepada Allah, Tuhan atas semesta dengan kerendahan hati yang besar dan pengabdian sepenuhnya. 3. Kita juga harus menyadari bukan banyak bicara yang membuat doa kita didengar, melainkan dengan kemurnian hati dan hati yang penuh dengan pertobatan. ${ }^{41}$

38. Mazmur 119:164 (TB-LAI)

39. Kardong, Benedict's Rule, 192.

40. Kardong, Benedict's Rule, 203.

41. Kardong, Benedict's Rule, 206. 
Berdasarkan pemaparan RB 19 dan 20, demikianlah kualitas yang seharusnya dimiliki di dalam setiap doa yang dinaikkan kepada Allah.

Doa menghasilkan penthos dalam hati para biarawan. Penthos atau yang dalam bahasa Latin disebut 'compunctio' memiliki arti sebagai 'kesedihan pertobatan. ${ }^{42}$ Semakin orang berdoa, semakin ia menyadari bahwa dirinya adalah seorang manusia yang berdosa, tetapi menerima anugerah dan kemurahan dari Allah. Oleh sebab itu, penting untuk membaca Mazmur dalam doa sebagai kesempatan untuk mendengarkan suara Allah, kemudian merespons melalui doa. ${ }^{43}$ Mendengar melalui firman dan menjawab dalam doa adalah percakapan llahi yang membawa orang semakin dekat pada Allah. Hal ini juga senada dengan pernyataan Stewart (seorang biarawan Benedictine) bahwa Divine Office merupakan waktu dan sarana yang tepat untuk berjumpa dengan Allah dan merupakan kesempatan berharga yang tidak boleh dilewatkan. ${ }^{44}$

Terkait dengan peranan doa untuk mendidik jiwa, St. Benediktus juga memberi penekanan mengenai pentingnya holy reading atau yang disebut dengan lectio divina dalam bahasa Latin. Penekanan utama pada lectio divina seperti yang dipaparkan dalam RB 48 merujuk pada sebuah perenungan yang mendalam dengan membaca dan merenungkan firman Tuhan dengan penuh doa (prayerful). ${ }^{45}$ Stewart menjelaskan bahwa di dalam praktiknya di dalam biara, pembacaan ini digunakan sebagai 'bekal'

42. Stewart, Prayer and Community, 49.

43. Vogue, Reading Saint Benedict, 143.

44. Stewart, Prayer and Community, 33.

45. Stewart, Prayer and Community, 37. Kardong juga menambahkan bahwa lectio divina dilakukan dengan pola tetap yang berulang, yaitu: dengarkan, renungkan, dan terapkan. 
untuk melakukan Divine Office. ${ }^{46}$ Proses ini disebut dengan rumination (Latin: ruminatio), sebuah proses yang dilakukan sapi ketika mengunyah rumput, yaitu praktik pembacaan suci dilakukan dengan lambat, tetapi menyentuh hati mengubah kehidupan ${ }^{47}$ Sebab, Lectio merupakan sebuah kesempatan untuk menjadi peka terhadap kehadiran Allah. ${ }^{48}$ Allah hadir dan seolah-olah berbicara secara langsung kepada para biarawan yang jiwanya sedang beristirahat di dalam Allah.

Allah hadir di tengah umat-Nya, Allah hadir di dalam kehidupan yang berdoa, dan Allah hadir dalam segala hal yang dilakukan umat-Nya. Kesadaran penuh akan kehadiran Allah merupakan hal utama yang membentuk kehidupan yang berdoa dalam tradisi Benedictine. ${ }^{49}$ Orangorang yang tidak menyadari kehadiran Allah, sesungguhnya tidak memahami pengertian dari doa yang dilakukan dengan cara yang berpola. Kehidupan orang-orang di dalam biara menjadi flourish, penuh dengan segala kebajikan karena kesadaran bahwa Allah hadir dalam hidup mereka, terkhusus di dalam dan melalui doa serta firman Tuhan.

\section{Bekerja sebagai Persembahan kepada Allah}

Kehidupan yang bekerja di biara dibahas dengan sangat masif di bagian ini. Ambrose Wathen membagi hal ini ke dalam beberapa bagian, sebagai berikut.

46. Stewart, Prayer and Community, 37.

47. Derkse, The Rule of Benedict for Beginners, 37.

48. Stewart, Prayer and Community, 37.

49. Stewart, Prayer and Community, 50. 
21-57, Disiplin dan Administrasi:

a. Deans and penitential code (Dekan dan kode penyesalan), 2130

b. Cellarer and his responsibilities (Bendahara dan tanggung jawab), 31-41

c. Discipline (Disiplin), 42-57

58-66, Pembaruan Biara:

a. Recruitment (Perekrutan), 58-62.

b. Order and hierarchy (Aturan dan Hierarki), $63-66 . .^{50}$

Dari pembagian ini, dapat dilihat bahwa bagian ini banyak membahas hal-hal yang bersifat administratif dan berbagai jenis pekerjaan yang dilakukan dalam komunitas biarawan. Hal yang menarik untuk diperhatikan di dalam bagian ini adalah bahwa St. Benediktus tidak pernah memisahkan antara disiplin yang bersifat administratif dan disiplin secara spiritual. Semua bersinergi membangun hidup spiritualitas yang utuh di tengah biara.

Whaten menyimpulkan bahwa chapter 42-57 dalam RB dapat dipadatkan dalam sebuah istilah yaitu disiplin. ${ }^{51}$ Kedisiplinan ini terkait dengan pekerjaan harian (manual labor) yang dilakukan di dalam biara. St. Benediktus menjelaskan dengan sangat baik alasan mengapa seorang biarawan harus tetap melakukan pekerjaan harian ketika berada dalam biara, "kemalasan adalah musuh bagi jiwa, oleh sebab itu pada waktu yang ditentukan saudara-saudara [para biarawan] harus melakukan pekerjaan

50. Ambrose G. Wathen, Silence: The Meaning of Silence in the Rule of St. Benedict (Washington: Cistercian, 1973), 11.

51. Wathen, Silence: The Meaning of Silence in the Rule of St. Benedict, 11. 
harian, dan lectio divina pada waktu lainnya." ${ }^{52}$ Adalbert de Vogue memaparkan bahwa sebagaimana Evagrius dan Cassian melihat betapa berbahayanya kemalasan bagi jiwa, demikian juga St. Benediktus. ${ }^{53}$ Kemalasan adalah kejahatan yang hanya bisa dilawan dengan cara melakukan pekerjaan. ${ }^{54}$ Para biarawan yang melakukan pekerjaannya dengan disiplin, sesungguhnya sedang berusaha memastikan jiwanya berada dalam kondisi yang baik dan menjauhi kejahatan.

St. Benediktus menunjukkan pentingnya seseorang untuk tetap melakukan manual labor, pekerjaan sehari-hari yang dipandang memiliki derajat yang sama dengan penyembahan di kapel atau perenungan firman yang dilakukan. ${ }^{55}$ Kesadaran ini terbentuk dari pemahaman bahwa kita ada di hadapan Allah yang selalu melihat kita (coram Deo). Selain itu, bekerja merupakan latihan untuk membentuk dan mempertahankan moral yang baik dengan rasa damai di hati. ${ }^{56}$ Frasa Latin, "animam suam custodiat" (terjemahan: preserve his life atau memelihara hidup) adalah ungkapan yang menjelaskan bagaimana seseorang mengasihi dirinya dengan cara yang benar sebagai hasil dari hidup yang bekerja. Nilai ini muncul sebagai dampak dari pemahaman St. Benediktus bahwa hal material dan hal spiritual adalah hal yang tidak berbeda dan tidak terpisah satu dengan yang

52. Kardong, Benedict's Rule, 382. Tulisan-tulisan lain sebelum St. Benediktus menunjukkan bahwa berbagai catatan lainnya juga turut memperhatikan hal ini.

53. Vogue, Reading Saint Benedict, 235.

54. Vogue, Reading Saint Benedict, 235.

55. Waal, Seeking God, 92.

56. Waal, Seeking God, 121. 
lain. ${ }^{57}$ Sebab, semua hal yang dilakukan adalah untuk menemukan Kristus dalam keseharian. Dengan demikian, tidak ada satu hal pun yang dilakukan tanpa seseorang menemukan Allah. Maka, kegagalan terbesar di dalam biara adalah ketika seseorang telah berusaha melakukan setiap aturan, tetapi tidak menemukan dan mengalami Allah.

\section{Perjalanan Kasih Menuju Kesempurnaan}

Vogue menyatakan bahwa bagian akhir dalam rules ini, yang dimulai dari RB 67-72, merupakan bagian lampiran. ${ }^{58}$ Lampiran ini banyak membahas mengenai bagaimana setiap praktik yang dilakukan di tengah biara seharusnya dilakukan dengan landasan kasih. Hidup yang penuh dengan kasih akan terlihat dengan jelas ketika seseorang melakukan berbagai tugas yang dilakukan. Salah satu yang menarik adalah St. Benediktus memberikan penegasan mengenai jenis kasih yang harus dimiliki oleh seorang biarawan (RB 72).

4. Demikian biarawan harus mempraktikkan semangat kasih ini dengan penuh kehangatan: ... 7. Tidak ada orang yang diperkenankan mencari kepentingan diri sendiri, melainkan apa yang menguntungkan orang lain. 8. Mereka harus menunjukkan kasih yang tidak egois kepada saudara yang lain. 9. Kiranya mereka takut (hormat) akan Allah karena kasih. 10. Mereka harus mengasihi kepala biara dengan ketulusan dan kerelaan yang penuh dengan kerendahan hati. 11. Kiranya mereka hanya mengutamakan Kristus, 12. Dan kiranya la memimpin kita sekalian ke dalam hidup yang kekal. ${ }^{59}$

57. Waal, Seeking God, 118.

58. Vogue, Reading Saint Benedict, 334.

59. Kardong, Benedict's Rule, 588. 
Kasih yang muncul dalam bentuk inklusi, di bagian awal dan akhir, menunjukkan peran yang sangat signifikan di dalam rules. Kasih kepada Allah dan sesama muncul dari sebuah hidup yang digerakkan oleh karena kasih Kristus.

Bab terakhir dalam RB, yaitu RB 73, sering disebut sebagai bagian epilog. Penekanan yang diberikan adalah bahwa biara dengan semua aturannya, baik dalam berdoa maupun bekerja, dimaksudkan untuk sebuah perjalanan to the perfection, kepada kesempurnaan yang senada dengan perkataan Kristus dalam Matius 5:48. Bagi orang yang memiliki keinginan yang mendalam untuk sempurna seperti Allah, haruslah mengupayakannya dengan penuh kesungguhan. ${ }^{60}$

Dengan kerendahan hati, St. Benediktus menyatakan bahwa aturan yang telah disusun ini tidak mampu membuat seseorang menjadi sempurna. Namun, kumpulan rules ini jika digabungkan dengan materi lainnya dapat membantu seseorang untuk mencapai kesempurnaan di dalam pengenalan akan Allah.

2. Tetapi untuk seseorang yang bersegera untuk mencapai kepenuhan hidup biara [conversatio/perubahan hidup], ada pengajaran-pengajaran dari Bapa-bapa Kudus. 3. Sebab halaman atau perkataan manakah dari Perjanjian Lama dan Perjanjian Baru yang tidak dapat membimbing seseorang untuk hidup? ... 8. Oleh sebab itu, apabila engkau hendak mencapai tempat tinggal surgawi, dengan tuntunan Kristus gunakanlah Aturan untuk para pemula yang telah kami buat ini. 9. Hanya dengan begitu engkau

60. Vogue, Reading Saint Benedict, 335. 
akan tiba dengan perlindungan Allah kepada puncak pengajaran dan kebajikan yang telah kami jabarkan. Amin." ${ }^{61}$

Dari hal ini, dapat disimpulkan bahwa dalam segala hal yang dilakukan ataupun tidak dilakukan di dalam biara, tujuannya hanya satu, yaitu perubahan dalam kasih untuk kembali kepada Allah.

Setiap model perkumpulan orang percaya jelas dapat menggunakan pola RB untuk membentuk sebuah formasi spiritual yang baik bagi jiwa yang menantikan Allah. Seminari sebagai sebuah wadah yang mempersiapkan para seminaris untuk melayani Allah dan sesama juga perlu memastikan bahwa semua orang yang bergabung memiliki kualitas kerohanian yang baik. Di tengah perubahan zaman dan berbagai penyesuaian kebutuhan, seminari perlu memastikan untuk menjalankan sebuah sistem pendidikan teologi yang seimbang, antara disiplin keilmuan dan pertumbuhan spiritual sebagai fokus dalam hidup spiritual yang holistik. Dengan demikian, proses penyesuaian konteks RB dan seminari juga perlu dilakukan untuk menerapkan aturan ini ke masa sekarang.

\section{Tantangan dalam Formasi Spiritual di Seminari}

Seminari adalah komunitas yang penting sebagai sarana formasi spiritual umat Allah, tetapi persoalan yang muncul paling besar di seminari adalah mengenai ketidakseimbangan. Fokus antara pengembangan akademik, hal-hal yang dipelajari di kelas seperti doktrin, bahasa,

61. Kardong, Benedict's Rule, 603. Dari bagian ini, dapat dilihat bahwa St. Benediktus memberi penekanan khusus bahwa otoritas tertinggi tetap ada pada firman Tuhan, kitab suci. Di samping rules yang telah ia buat, ada banyak tulisantulisan baik lainnya yang dapat menolong seseorang untuk memiliki hidup yang sempurna dalam perubahan oleh karena pertolongan Kristus. 
pembahasan sejarah yang cenderung sulit seringkali membuat para seminaris kehilangan tujuan dan kepekaan sebagai seorang hamba yang sedang belajar. Umumnya, kecenderungan yang timbul adalah hanya melihat diri sebagai seorang akademisi, tanpa berfokus untuk membangun karakter diri secara utuh yang memiliki kekuatan spiritual. Hal ini yang kemudian menjadi kritik dari pengamatan yang dilakukan oleh Benjamin B. Warfield dalam sebuah artikel yang ia tulis mengenai mahasiswa teologi.

Fokus utama pada akhirnya bukanlah pada kemampuan intelektual, melainkan pada kesehatan kerohanian. Seorang pelayan harus belajar, ... Akan tetapi sebelum dan bahkan melampaui belajar itu sendiri, seorang pelayan haruslah saleh. Tidak ada yang lebih fatal, daripada berpikir bahwa ada yang memiliki posisi yang lebih tinggi antara satu dengan yang lain [antara belajar dan kesalehan]. ${ }^{62}$

Tulisan yang lebih baru datang dari Bryan Stoudt, seorang hamba Tuhan dan juga life coach yang memberi tanggapannya tentang hidup sebagai seminaris. Tantangan besar yang datang pada diri seorang seminaris adalah bahaya berhala. ${ }^{63}$ Berhala yang dimaksud adalah ketika kecerdasan akademik 'mengaburkan' kehadiran Allah sebagai pribadi utama yang harus dikejar di dalam hidup sang seminaris. ${ }^{64}$ Dari pembahasan di atas, dapat dilihat bahwa permasalahan mengenai ketidakseimbangan adalah hal besar yang memerlukan penanganan yang

62. Benjamin B. Warfield, "The Religious Life of Theological Students," The Master's Seminary Journal 6 (1995): 182.

63. Bryan Stoudt, "If I Had a Second Shot at Seminary (Pt. 2)," AIC, 24 Oktober 2019, diakses 14 Juli 2021, https://amicalled.com/second-shot-seminarypt-2/.

64. Stoudt, "If I Had a Second Shot at Seminary (Pt. 2)." 
tepat guna mendukung pertumbuhan spiritual para seminaris. Beberapa permasalahan dalam hidup seminaris adalah sebagai berikut.

\section{Penekanan yang Berlebihan pada Pembentukan Kualitas Akademik}

Belajar di tengah seminari sebagai wadah untuk mempersiapkan para hamba Tuhan di masa sekarang jelas memiliki tujuan yang sangat penting, yaitu untuk berjumpa dengan Allah sebagai dasar hidup spiritual. ${ }^{65}$ Helmut Thielicke mencatatkan bahwa permasalahan utama seminaris adalah kemampuan intelektual (dalam kaitan dengan studi teologi) yang melampaui kapasitas spiritual. ${ }^{66}$ Kondisi ini jelas adalah sebuah penyakit, dan jenis penyakit ini disebabkan oleh kondisi kepala yang penuh dan tidak mampu 'dicerna' lebih lanjut oleh jiwa manusia. ${ }^{67}$ Ketidakseimbangan antara kemampuan intelektual dan pertumbuhan rohani para seminaris menyebabkan sulitnya perjumpaan dengan Allah.

Kritik yang lebih baru juga disampaikan oleh Jonathan Parnell dengan mengingatkan para seminaris bahwa Allah memilih kita di dalam kelemahan kita, maka tidak perlu terlalu bangga dengan kemampuan

65. David Mathis dan Jonathan Parnell, How to Stay Christian in Seminary (Wheaton: Crossway, 2014), 41.

66. Helmut Thielicke, A Little Exercise for Young Theologians (Grand Rapids: Eerdmans, 1965), 16. Thielicke melihat kondisi yang ia sebut sebagai intellectual hypertrophy sebagai penyakit yang sesungguhnya, sebuah demam tinggi yang dialami oleh para seminaris. Oleh sebab itu, ia melihat lebih lanjut bahwa untuk melawan hal tersebut, para seminaris harus melihat bahwa pembelajaran intelektual yang diterima sebagai sebuah tantangan kepada iman. Jika tidak demikian, yang terjadi adalah kita akan meninggalkan iman di dalam Kristus dan beralih percaya pada tokoh-tokoh teologi lainnya.

67. Mathis dan Parnell, How to Stay Christian in Seminary, 16. 
intelektual yang dimiliki. ${ }^{68}$ Dengan demikian dapat disimpulkan bahwa penekanan yang berlebihan pada kemampuan intelektual telah menghasilkan calon hamba Tuhan yang bahkan dengan mudah melupakan makna keberadaannya di tengah-tengah seminari. Lebih daripada itu, ia melupakan makna mengenai keberadaan diri sebagai seorang berdosa yang telah menerima kemurahan Allah.

\section{Ritual Keagamaan yang Tidak Menghasilkan Relasi bersama dengan Allah}

Di antara berbagai permasalahan spiritual yang dihadapi oleh para seminaris, salah satu masalah yang muncul adalah ketika mereka tidak bisa lagi merasakan kehadiran Allah. Pernyataan yang sangat marak terdengar adalah ada banyak orang yang berpendapat bahwa mereka lebih spiritual sebelum mereka masuk ke seminari dibandingkan dengan setelah berada di seminari. Kesibukan akademik, tugas harian, tantangan pelayanan terkadang membuat seminaris melewatkan kesempatan untuk berdoa dan membangun hubungan bersama Allah. Firman Tuhan yang semula menjadi dasar pertumbuhan kerohanian, kini tidak lagi menggairahkan sang seminaris.

68. Mathis dan Parnell, How to Stay Christian in Seminary, 52. David Mathis dan Jonathan Parnell adalah dua orang hamba Tuhan yang masih aktif melayani hingga sekarang. Mereka menuliskan buku ini untuk ditujukan kepada para seminaris agar terus berjuang membentuk kehidupan yang bertumbuh dalam kerohanian. Dalam sub bab yang dituliskan oleh Parnell, ia mengutip perkataan Paulus terkait dengan panggilan Allah yang besar kepada orang-orang yang tidak memiliki kelebihan apa-apa di mata dunia. Teks yang dikutip adalah dari 1 Korintus 1:26, "Ingat saja, saudara-saudara, bagaimana keadaan kamu, ketika kamu dipanggil: menurut ukuran manusia tidak banyak orang yang bijak, tidak banyak orang yang berpengaruh, tidak banyak orang yang terpandang." 
Di sisi yang lain, permasalahan yang juga nampak adalah manipulasi yang dilakukan terkait dengan ritual yang dilakukan. Doa adalah sebuah bentuk relasi bersama Allah, maka tanpa relasi, doa merupakan sebuah bentuk manipulasi kepada Allah. ${ }^{69}$ Kondisi seperti ini sangat banyak terjadi di tengah pendidikan teologi. Sebuah penelitian dalam sebuah tulisan berjudul "Educating Clergy" menuturkan bahwa, "ada banyak pengajar yang menyadari bahwa bahkan ketika mereka sangat teratur dalam melakukan ritual seperti berdoa, mereka menyadari bahwa relasi bersama Allah-mengalami kehadiran Allah-belum terasa dengan nyata." ${ }^{70}$ Ritual tanpa relasi adalah upaya manipulasi yang dilakukan untuk memuaskan kebutuhan dan keinginan pribadi. Dampak yang ditimbulkan adalah seminaris melakukan semua ritual, tanpa sungguh-sungguh mengalami Allah dalam hidup secara personal.

Permasalahan yang dihadapi oleh para seminaris ini seringkali berlanjut pada mempersalahkan para pemimpin (pihak sekolah) karena tingkat kerohanian seminaris yang tidak bertumbuh. Pemikiran ini perlu diperbaiki dengan kesadaran bahwa seseorang yang menyertakan Allah dalam ibadahnya, pertemuan yang intensional bersama Allah, pasti berjumpa dengan Allah di dalam ibadah yang dilakukannya. ${ }^{71}$ Permasalahan utama dalam kerohanian adalah ketika seseorang tidak sungguh-sungguh menyertakan Allah dalam ritual keagamaan yang

69. Carnegie Samuel Calian, The Ideal Seminary (Louisville: Westminster John Knox, 2001), 102.

70. Charles R. Foster dkk., Educating Clergy: Teaching Practices and Pastoral Imagination (San Francisco: Jossey-Bass, 2005), 110.

71. Warfield, "The Religious Life of Theological Students," 190. 
dilakukan. Meski demikian, pihak sekolah (seminari) juga harus tetap menyertakan ruang belajar untuk formasi spiritual para seminaris.

Kualitas Karakter yang Buruk sebagai Antitesis Hidup sebagai Hamba Tuhan

Permasalahan seminaris yang kehilangan kepekaan 'spiritual' pasti berujung kepada permasalahan karakter. Berbagai hal akan muncul sebagai akibat dari orang-orang yang tidak lagi 'rohani'. Thielicke sekali lagi memberikan pendapatnya, bahwa seseorang yang berhenti menjadi seorang yang rohani, bahkan ketika pengajarannya bersifat ortodoks dan tidak menyimpang, sesungguhnya telah mati secara perlahan-lahan tanpa ia sadari. ${ }^{72}$ Pengajaran yang benar tanpa disertai relasi dengan Allah hanya menghasilkan sebuah hidup yang penuh dengan kemunafikan.

Salah satu contoh dari masalah seorang yang menyebut diri sebagai hamba Tuhan, tetapi kehilangan sense kerohanian adalah kemalasan. ${ }^{73}$ Kemalasan adalah hal yang muncul paling pertama sebagai akibat dari hati yang tidak lagi berpusat kepada Allah. Gregory the Great melihat betapa buruk permasalahan kemalasan ini dalam karyanya, Morals on the Book of Job,

"Tidak ada hal yang terjadi di dunia tanpa sebab." Terkait dengan hal ini maka sering terjadi bahwa bahkan orang yang malas pun sebenarnya menerima kesanggupan, agar ia dapat lebih pantas dihukum karena kecerobohannya, karena ia mencemooh untuk membiasakan dirinya dengan apa yang dapat ia lakukan, mencapai sesuatu tanpa bekerja. ${ }^{74}$

72. Thielicke, A Little Exercise for Young Theologians, 36.

73. Warfield, "The Religious Life of Theological Students," 184.

74. Kevin M. Clarke, ed., The Seven Deadly Sins: Sayings of the Fathers of the Church (Washington: The Catholic University of America, 2018), 117. 
Setiap hamba Tuhan diberikan kemampuan oleh Allah yang telah memanggilnya, akan tetapi ada banyak kali di mana orang-orang seperti seminaris kehilangan sudut pandang ini. Oleh sebab itu, kemalasan jelas bertentangan dengan konsep mempersembahkan diri seutuhnya kepada Allah sebagai Tuan yang dilayani.

Merespons permasalahan spiritual dari para seminaris, maka perlu dilakukan sebuah pendalaman lebih lanjut mengenai cara atau metode yang dapat diterapkan dalam komunitas orang percaya seperti seminari. Di dalam sebuah penelitian dari Biola University melalui sebuah jurnal yang diterbitkan dengan judul "A Call for Evangelical Monasticism", ditunjukkan bahwa pergerakan spiritual Injili dalam konteks sekarang perlu memperhatikan kehadiran biara. Sangat penting untuk melihat bahwa biara telah membentuk kehidupan spiritual umat Tuhan dengan sangat baik, hal ini nampak dari berbagai tulisan dalam berbagai literatur yang mendukung. ${ }^{75}$ Salah satu karya yang sangat kuat untuk melakukan formasi terhadap hidup spiritual adalah The Rule of St. Benedict.

\section{Penggunaan The Rule of St. Benedict sebagai Dasar Formasi Spiritual di Seminari}

RB telah menjadi sebuah karya yang bertahan sejak sangat lama di dalam literatur Kristen sepanjang masa dengan kualitas yang sangat baik terkait dengan formasi spiritual. Beberapa pihak menggunakannya di dalam menjalankan sebuah biara, beberapa yang lain menerapkannya di dalam

75. Greg Peters, "Special Theme Section: A Call for Evangelical Monasticism," Journal of Spiritual Formation and Soul Care 10, no. 2 (2017): 250. 
konteks nonbiara. ${ }^{76}$ Keunggulan utama aturan-aturan ini terkait dengan pembentukan spiritual adalah karena aturan ini bersifat sangat praktis dan aplikatif. $^{77}$ Bila diterapkan dalam konteks seminari, kekuatan RB yang formatif diharapkan dapat menjadi pijakan bagi formasi spiritual para seminaris.

\section{Keseimbangan Doa dan Bekerja sebagai Dasar Pijakan Formasi Spiritual}

Meskipun St. Benediktus tidak pernah menggunakan istilah ini secara langsung, RB dikenal dengan frasa ora et labora yang artinya berdoa dan bekerja. Alasannya adalah karena penekanan utama dalam rules ini secara khusus pada praktik berdoa dan bekerja. Keseimbangan ini telah menghasilkan sebuah kehidupan spiritual yang otentik dan holistik meskipun penerapannya di tengah seminari jelas memerlukan penyesuaian dengan harapan formasi spiritual serupa juga terjadi di tengah seminari. Stewart menjelaskan maksud ini dengan pemaparan bahwa setiap praktik dan disiplin yang dilakukan dalam biara menolong biarawan untuk mengutamakan Allah daripada diri sendiri. ${ }^{78}$ Warfield memberi penekanan pada makna utama dari belajar dengan mengatakan bahwa, "Engkau tidak akan pernah berhasil dalam hidup spiritual dalam Seminari Teologi sampai ketika pekerjaan [pembelajaran] di seminari menjadi latihan spiritual harian yang membesarkan hati, menumbuhkan jiwa, dan yang memuji keindahan

76. Greg Peters, tinjauan dari The Rule of St. Benedict of Nursia, oleh St. Benedict, Journal of Spiritual Formation \& Soul Care 1, no. 1 (2008): 107.

77. Peters, tinjauan dari The Rule of St. Benedict of Nursia, 107.

78. Stewart, Prayer and Community, 88. 
Sang Pencipta dan Penebus.."79 Dengan demikian, praktik bekerja (dalam hal ini juga belajar) merupakan kesempatan untuk meninggikan Allah ketika dilakukan dengan semangat dan disiplin yang benar.

Di dalam penerapan rules ini, St. Benediktus memberikan penekanan yang berbeda antara belajar dan juga bekerja. Bekerja dikhususkan dalam bentuk pekerjaan harian yang memang dimaksudkan untuk mencukupi kebutuhan jasmani para biarawan, sedangkan belajar adalah dengan membaca literatur yang mendukung kualitas jiwa mereka. Meski natur dari biara dan seminari jelas memiliki perbedaan terkait dengan melihat deskripsi bekerja, akan tetapi hal yang perlu diperhatikan adalah porsi bekerja di dalam komunitas harus senantiasa berjalan beriringan dengan kualitas doa dan pembacaan firman Tuhan.

Cara terbaik untuk menjalankan proses belajar dan bekerja yang seimbang ini adalah ketika seseorang sungguh-sungguh menjalankan proses belajar yang penuh dengan doa (prayerful learning). Kondisi formatif seperti ini yang menghasilkan proses transformasi dari pembelajaran yang hanya bersifat informatif menjadi sebuah intimasi dengan Allah. ${ }^{80}$ Perjumpaan dengan Allah yang hidup dalam proses pembelajaran menolong setiap seminaris untuk memiliki sebuah kehidupan belajar yang bergairah dan transformatif.

Prologue yang dituliskan oleh St. Benediktus juga menjelaskan bahwa doa menjadi awal sebelum melakukan sebuah pekerjaan, bahkan pekerjaan yang baik, agar Allah membuatnya menjadi sempurna (RB 
Prologue 4). ${ }^{81}$ Tanpa doa, mustahil manusia dapat mengalami relasi yang telah ditebus oleh Allah. Relasi doa dan belajar digambarkan sebagai hubungan yang saling terkait satu dengan yang lain. Seperti yang dikatakan oleh Kelly M. Kapic, "Pembelajaran menerangkan doa kita, dan doa menghidupkan pembelajaran kita. Kita tidak bisa memilih antara doa dan belajar; teologi yang setia membutuhkan belajar yang penuh dengan doa." ${ }^{\prime 2}$ Maka, bagi seseorang yang belajar, doa adalah sebuah hal inti yang tidak mungkin dilewatkan. Tidak ada kehidupan belajar yang baik tanpa kehidupan doa yang baik.

St. Benediktus tidak pernah memisahkan antara doa dan pembacaan serta perenungan firman Tuhan. Di dalam doa komunal, para biarawan (demikian juga dengan para seminaris) selalu membaca firman. Poinnya ada pada pemahaman bahwa jiwa yang belajar membutuhkan lebih dari sekadar kata (word), melainkan Firman Yang Hidup (Living Word), Kristus sendiri. ${ }^{83}$ Proses aktivitas (belajar) yang memberi penekanan pada prayerful study dapat menghasilkan seminaris dengan kualitas yang saleh.

Kehadiran Otoritas dalam Komunitas yang Menciptakan Kualitas Kebajikan

RB dibuat dalam konteks hidup bersama, coenobitic life, yang sesuai dengan pemahaman bahwa seseorang bertumbuh secara spiritual dalam kondisi optimal dan holistik ketika berada dalam komunitas. Seluruh

81. Terrence G. Kardong, The Life of St. Benedict by Gregory the Great: Translation and Commentary (Collegeville: Liturgical, 2009), 3.

82. Kelly M. Kapic, A Little Book for New Theologians: Why and How to Study Theology (Downers Grove: IVP, 2012), 70.

83. Mathis dan Parnell, How to Stay Christian in Seminary, 40. 
tatanan kehidupan diatur dan diawasi oleh Abbot, selaku representasi Allah. Poin penting yang perlu diperhatikan adalah mengenai kehadiran pihak yang memiliki otoritas-membawa kehadiran Kristus-di tengah komunitas. Tujuan dari sistem yang diatur seperti ini adalah agar setiap biarawan memiliki kesempatan yang sama untuk menghasilkan sebuah model kehidupan yang tertentu. Hasil yang dimaksudkan tentunya untuk mencapai kualitas kebajikan yang diharapkan dengan takut akan Allah. Hal yang ultima adalah terkait dengan pencapaian kesempurnaan di hadapan Allah melalui komunitas.

Serupa dengan biara, kekuatan utama sebuah seminari terletak pada kehadiran komunitas yang kuat. Kekuatan ini didorong oleh kesamaan panggilan yang mendasari keberadaan seseorang di seminari. Warfield menegaskan bahwa kekuatan panggilan terletak pemahaman bahwa, tugas yang Allah berikan adalah besar dan Dia menganugerahkan kekuatan yang tak terbatas untuk melakukannya. ${ }^{84}$ Sebagai dampak dari panggilan ini, maka komitmen akan muncul sebagai dasar pengikat hidup yang berdedikasi. Kesungguhan yang dimaksud adalah hidup yang diarahkan sepenuhnya kepada Allah dengan janji untuk memberi keseluruhan hidup bagi Allah.

Dengan menjalankan hidup yang tunduk pada otoritas-sebuah bentuk konkrit hidup yang takut akan Allah-maka biarawan dan juga seminaris dapat menghasilkan berbagai macam kebajikan. Ketaatan, sikap hati yang menjauhi dosa, dan kerendahan hati adalah bentuk-bentuk nyata dari hidup yang tunduk pada otoritas. Kualitas kebajikan hanya muncul 
sebagai akibat dari kehidupan spiritual yang baik, atau hidup spiritual yang baik akan menghasilkan berbagai kebajikan dalam hidup seminaris. Poin penting kehidupan yang berada di bawah otoritas terletak pada hidup yang senantiasa takut akan Allah.

\section{Kesimpulan}

Perjalanan umat Tuhan dalam sepanjang abad menunjukkan bahwa perkembangan kekristenan selalu berbanding lurus dengan perkembangan pendidikan teologi. Kekuatan pola yang dihasilkan dalam sistem pendidikan teologi di sepanjang zaman adalah penerapan doa dan pembacaan firman Tuhan. Pola kehidupan yang berfokus pada firman Tuhan dan doa terus mengalami perkembangan. Perkembangan pendidikan teologi terus memperlihatkan kemajuan yang pesat dan didukung oleh sistem yang semakin baik. Di masa sekarang, model pendidikan teologi yang muncul dan berkembang adalah seminari. Sebagai salah satu model pendidikan teologi, seminari juga perlu memiliki sebuah model atau pola yang membantu proses formasi spiritual dapat tercipta dengan baik.

Melihat dari sejarah, maka pola yang dianggap unggul untuk membantu proses formasi spiritual dapat terjadi adalah dengan menggunakan The Rule of St. Benedict dari konteks biara di abad pertengahan. Keberadaan $R B$ di tengah-tengah komunitas orang percaya sebagai sarana formasi spiritual selama berabad-abad juga hadir untuk menunjukkan betapa pentingnya keseimbangan di dalam kehidupan seseorang. Doa dan bekerja adalah hal yang sangat esensial. Oleh sebab itu, kedua hal ini harus berada dalam kondisi yang seimbang. Melakukan 
keseluruhan rules ini jelas tidak dimungkinkan di dalam konteks seminari. Seminari memiliki model pendidikan, tantangan zaman, dan permasalahan yang berbeda. Menarik untuk diperhatikan bahwa setiap pihak yang menerapkan aturan ini dengan kesamaan intensi bahwa Allah menyempurnakan segala sesuatu yang dilakukan manusia akan memiliki sebuah pola hidup yang takut akan Allah!

\section{Daftar Pustaka}

\section{Buku}

Bradley, James E., dan Richard A. Muller. Church History: An Introduction to Research, Reference Works, and Methods. Grand Rapids: Eerdmans, 1995.

Calian, Carnegie Samuel. The Ideal Seminary. Louisville: Westminster John Knox, 2001.

Cetuk, Virginia Samuel. What to Expect in Seminary: Theological Education as Spiritual Formation. Nashville: Abingdon, 1998.

Clarke, Kevin M., ed. The Seven Deadly Sins: Sayings of the Fathers of the Church. Washington: The Catholic University of America, 2018.

Derkse, Wil. The Rule of Benedict for Beginners: Spirituality for Daily Life.

Diterjemahkan oleh Martin Kessler. Collegeville: Liturgical, 2003.

Dockery, David S., ed. Theology, Church, and Ministry: A Handbook for Theological Education. Nashville: B\&H, 2017.

Foster, Charles R., Lisa Dahill, Larry Golemon, dan Barbara Wang Tolentino. Educating Clergy: Teaching Practices and Pastoral Imagination. San Francisco: Jossey-Bass, 2005.

González, Justo L. The History of Theological Education. Nashville: Abingdon, 2015.

Kapic, Kelly M. A Little Book for New Theologians: Why and How to Study Theology. Downers Grove: IVP, 2012.

Kardong, Terrence G. Benedict's Rule: A Translation and Commentary. Collegeville: Liturgical, 1996.

Kardong, Terrence G. The Life of St. Benedict by Gregory the Great: Translation and Commentary. Collegeville: Liturgical, 2009. 
Kartika, Casthelia. "Origen on Spiritual Reading of Scripture and Prayer as Divine Pedagogy for the Perfection of Life." Disertasi D.Th., Lutheran Theological Seminary, 2017.

Mathis, David, dan Jonathan Parnell. How to Stay Christian in Seminary. Wheaton: Crossway, 2014.

Sittser, Gerald L. Water from a Deep Well: Christian Spirituality from Early Martyrs to Modern Missionaries. Downers Grove: IVP Books, 2010.

Stewart, Columba. Prayer and Community: The Benedictine Tradition. Maryknoll: Orbis, 1998.

Thielicke, Helmut. A Little Exercise for Young Theologians. Grand Rapids: Eerdmans, 1965.

Vogue, Adalbert De. Reading Saint Benedict: Reflections on the Rule. Collegeville: Cistercian, 1994.

Waal, Esther de. Seeking God: The Way of St. Benedict. Norwich: Canterbury, 1999.

Wathen, Ambrose G. Silence: The Meaning of Silence in the Rule of St. Benedict. Washington: Cistercian, 1973.

White, Carolinne, ed. The Rule of St Benedict. London: Penguin Classics, 2008.

Wilson-Hartgrove, Jonathan. New Monasticism: What It Has to Say to Today's Church. Grand Rapids: Brazos, 2008.

Woodbridge, John D., dan Frank A. James III. Church History: From PreReformation to the Present Day: The Rise and Growth of the Church in Its Cultural, Intellectual, and Political Context. Vol. 2. Grand Rapids: Zondervan, 2013.

\section{Jurnal}

Clemmons, William. "Spiritual Formation in Seminary Education." Review and Expositor 101 (2004): 41-66.

Hinson, E. Glenn. "The Spiritual Formation of the Minister as a Person." Sage Journal Review \& Expositor 70, no. 1 (1973): 73-85.

Hopkins, Dwight N. "The Purposes of Theological Education." Theological Education 51, no. 2 (2018): 39-47.

Peters, Greg. "Special Theme Section: A Call for Evangelical Monasticism." Journal of Spiritual Formation and Soul Care 10, no. 2 (2017): 24864. 
Porter, Steven L., Steven J. Sandage, David C. Wang, dan David C. Hill. "Measuring the Spiritual, Character, and Moral Formation of Seminarians: In Search of a Meta-Theory of Spiritual Change." Journal of Spiritual Formation and Soul Care 12, no. 1 (2019): 524.

Reisz, Jr., H. Frederick. "Assessing Spiritual Formation in Christian Seminary Communities: Lutheran Theological Southern Seminary." Theological Education 39, no. 2 (2003): 29-40.

Warfield, Benjamin B. "The Religious Life of Theological Students." The Master's Seminary Journal 6 no. 2 (1995): 181-95.

\section{Website}

Stoudt, Bryan. "If I Had a Second Shot at Seminary (Pt. 2)." AIC, 24 Oktober 2019. Diakses 14 Juli 2021. https://amicalled.com/second-shotseminary-pt-2/. 